\title{
Right Colonic Diverticular Perforation With Lateral Abdominal Wall Abscess: A Rare Occurrence
}

\author{
Gabriel Rodrigues $^{\mathrm{a}, \mathrm{c}}$, Vinod Kumar Singhal ${ }^{\mathrm{a}}$, Faris Dawood ${ }^{\mathrm{a}}$, Ramesh Pillutla ${ }^{\mathrm{b}}$
}

\begin{abstract}
Colonic diverticulosis is a common disease affecting a significant aged population in the Western world and can produce a wide range of clinical presentations varying from minimal clinical discomfort to life-threatening complications. Though left sided colonic diverticulosis is common, we present a rare case of a young Asian male with right sided colonic diverticular perforation and abscess which was successfully treated surgically.
\end{abstract}

Keywords: Diverticula; Perforation; Peritonitis; Abscess; Surgery

\section{Introduction}

Colonic diverticula are protrusions of the mucosa through the outer muscular layers, which are usually abnormally thickened, to form narrow necked pouches [1]. Diverticular disease of the colon covers a wide clinical spectrum: from an incidental finding to symptomatic uncomplicated disease to diverticulitis. A quarter of patients with diverticulitis will develop potentially life-threatening complications including perforation, fistulae, obstruction or stricture. In Western countries diverticular disease predominantly affects the left colon, its prevalence increases with age and its causation has been linked to a low dietary fiber intake [2]. Right colonic diverticular disease is uncommon and is the reason for reporting this case.

\section{Manuscript accepted for publication August 14, 2013}

${ }^{a}$ Departments of General Surgery, NMC Specialty Hospital, Dubai, UAE

${ }^{b}$ Departments of Radiodiagnosis, NMC Specialty Hospital, Dubai, UAE

${ }^{\mathrm{c} C o r r e s p o n d i n g ~ a u t h o r: ~ G a b r i e l ~ R o d r i g u e s, ~ S p e c i a l i s t ~ G e n e r a l ~ a n d ~}$

Laparoscopic Surgeon NMC, Specialty Hospital, PO Box 7832, Dubai,

UAE. Email: gabyrodricks@gmail.com

doi: http://dx.doi.org/10.4021/jcs193w

\section{Case Report}

A 26-year-old Nepali male presented to the ER with localized pain in the right lower abdomen and low grade fever of 3 days duration. There were no other constitutional, gastrointestinal or genitourinary symptoms. General physical examination was unremarkable. Per abdominal examination revealed a tender mass of $6 \times 5 \mathrm{~cm}$ in the right lumbar and iliac regions with guarding but no rigidity and rebound tenderness. The rest of the abdomen was normal. A provisional clinical diagnosis of appendicular mass was made and the patient was subjected to further investigations. There was leucocytosis $\left(12.3 \times 10^{9} / \mathrm{L}\right)$ with neutrophilia. As ultrasonography (USG) of the abdomen was inconclusive due to increased bowel gas shadows, a CT abdomen was done which revealed multiple cecal and ascending colonic diverticula with air pockets and fluid in the right lateral abdominal wall and localized peritoneal thickening suggestive of an abscess secondary to diverticular perforation (Fig. 1). Rest of the large bowel was normal. Patient was subjected to emergency laparotomy and

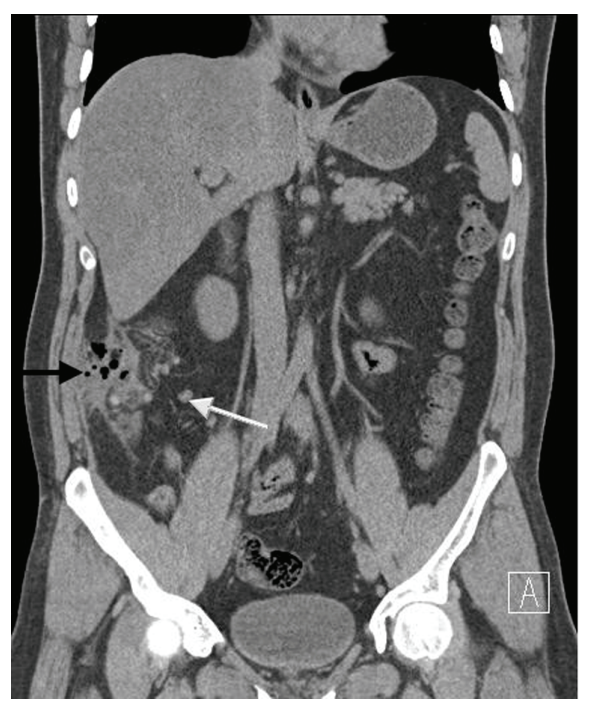

Figure 1. CT scan of abdomen showing multiple ascending colon diverticulae (white arrow) and perforation with lateral abdominal wall perforation (black arrow). 
was found to have similar findings as CT abdomen. The ascending colon at the site of diverticular perforation was stuck to the lateral peritoneum which was released and a perforation was identified. Around $50 \mathrm{~mL}$ of pus was drained and a right hemicolectomy with an ileotransverse anastomosis was executed. Rest of the colon was found to be normal with no diverticulae. The histopathology confirmed the intraoperative diagnosis. Postoperatively patient had an uneventful recovery and on follow up is doing well.

\section{Discussion}

Diverticular disease of the right colon is not common, especially in Western countries but is more commonly seen in Asian populations and affects younger patients. Its pathogenesis and relationship to left-sided diverticular disease remains unclear and occurs in two different clinical forms, the 'usual' and 'hidden' variants. Often the disease is congenital and the clinical manifestations presenting at onset simulate the signs and symptoms typical of other diseases, such as acute appendicitis, appendicular abscess or caecal carcinoma $[2,3]$.

Diagnosis is primarily by barium enema and colonoscopy, but computed tomography (CT) is increasingly being used to assess and treat complications such as abscess or fistula, or to provide alternative diagnoses if diverticulosis is not confirmed [4].

Initial therapy for uncomplicated diverticulitis is supportive, including monitoring, bowel rest and antibacterials. CT is used to guide percutaneous drainage of abscesses to avoid surgery or allow it to be performed as an elective procedure. Surgery is indicated for complications of acute diverticulitis, including failure of medical treatment, gross perforation, and abscess formation that cannot be resolved by percutaneous drainage. Complications of chronic diverticulitis (fistula formation, stricture and obstruction) are also usually treated surgically. However, the indications for, and the timing and staging of operations for diverticular disease are often difficult decisions requiring sound clinical judgment. Factors such as the number of episodes of inflammation, the age of the patient, and his/her overall medical condition play a role in determining whether or not a patient should undergo surgical resection. Prophylactic resection to avoid complications is not justified $[4,5]$.

Diverticular disease of the colon is the most common cause of acute lower gastrointestinal hemorrhage, which can be massive. Although majority of patients stop bleeding spontaneously, angiographic and surgical treatment may be required in intractable cases [2].

\section{Conflict of Interest}

Nil.

\section{Source of Funding}

Nil.

\section{References}

1. Pfeifer J. Diverticulitis. Acta Chir Iugosl. 2008;55(3):97102.

2. Castronovo G, Ciulla A, Tomasello G, Damiani S, Maiorana AM. Diverticular disease of right colon. Clinical variants and personal experience. Chir Ital. 2006;58(2):213-217.

3. Kang JY, Melville D, Maxwell JD. Epidemiology and management of diverticular disease of the colon. Drugs Aging. 2004;21(4):211-228.

4. Piccolini M, Francia L, Rosa C, Battaglia A, Biandrate F, Pesenti Campagnoni A, Pandolfi U. [Complicated diverticular disease of the right colon. Diagnostic and therapeutic difficulties: our experience]. Chir Ital. 2003;55(6):871-877.

5. Hildebrand P, Kropp M, Stellmacher F, Roblick UJ, Bruch HP, Schwandner O. Surgery for right-sided colonic diverticulitis: results of a 10-year-observation period. Langenbecks Arch Surg. 2007;392(2):143-147. 